\title{
Evaluación e intervención educativa en el aula con alumnado disruptivo dentro del marco de una escuela inclusiva
}

Badia Martín, M. del Mar; Daura Luján, Gisela

Evaluación e intervención educativa en el aula con alumnado disruptivo dentro del marco de una escuela inclusiva

Revista Educación, vol. 42, núm. 2, 2018

Universidad de Costa Rica, Costa Rica

Disponible en: http://www.redalyc.org/articulo.oa?id=44055139008

DOI: https://doi.org/10.15517/revedu.v42i2.24178

Esta obra está bajo una Licencia Creative Commons Atribución-NoComercial-SinDerivar 3.0 Internacional. 


\title{
Evaluación e intervención educativa en el aula con alumnado disruptivo dentro del marco de una escuela inclusiva
}

\author{
Evaluation and educational intervention in the classroom with disruptive students in the framework of an inclusive \\ school
}

M. del Mar Badia Martín [1]

Universidad Autónoma de Barcelona, España

mar.badia@uab.cat

Gisela Daura Luján [2]

Institut Roquetes, España

gdaura@xtec.cat
DOI: https://doi.org/10.15517/revedu.v42i2.24178

Redalyc: http://www.redalyc.org/articulo.oa?id=44055139008

Recepción: 05 Mayo 2016

Aprobación: 20 Marzo 2018

\section{ReSUMEN:}

La investigación Evaluación e intervención educativa con alumnos disruptivos dentro del marco de una escuela inclusiva, de la cual se deriva este artículo, se ha realizado durante el primer y segundo trimestre del curso escolar 2015-2016. El objetivo principal ha sido evaluar a los agentes implicados en el aula en el marco de una escuela ordinaria, donde se presenta alumnado disruptivo. Se elaboraron una serie de propuestas, y estrategias metodológicas para profesorado, que le permitiera entender y sensibilizarse de la problemática conductual de una parte de sus estudiantes y generar respuestas adecuadas a sus necesidades. Se partió de la observación y análisis de un curso de primero de educación secundaria obligatoria, a partir de ahora $\mathrm{ESO}$ (26 estudiante) y se detectó a quienes, por sus características, se consideró estudiantado disruptivo. A partir de esta detección, se abordaron las consecuencias que esto provoca en el funcionamiento rutinario, sus posibles causas, y se analizaron las percepciones que este grupo tenía de estas situaciones de disrupción. El personal implicado (de tutoría, docentes de las materias, jefaturas de estudios, directivo, departamento de orientación, grupo de mediación, conserjería... ) a partir de entrevistas y cuestionarios, ayudó a obtener conclusiones útiles para conseguir los objetivos propuestos. Los resultados avalan que las características familiares, la implicación y participación en todo el proceso educativo han sido de gran utilidad para saber cuál es la percepción que tienen de la escuela, del aula, del alumnado y de todo el personal docente, para poder establecer una serie de herramientas válidas para mejorar su comportamiento. Entre algunos de los datos obtenidos se puede observar unos resultados muy parecidos respecto a la dimensión relacional (conflicto) y a la dimensión de desarrollo (autonomía y moralidad-religiosidad). Por lo que respecta a la dimensión de estabilidad, tanto estudiantes como familias dan mucha importancia a la organización y planificación de las actividades y responsabilidades de la familia, y con menos grado al que hace referencia a las normas y procedimientos establecidos a la misma familia.

Palabras Clave: Educación secundaria obligatoria, alumnado disruptivo, familias, docentes, aprendizaje.

\section{ABSTRACT:}

The present research entitled "Evaluation and educational intervention with disruptive students within the framework of an inclusive school" was conducted during the first and second quarters of the 2015-2016 school year. The main objective was to

\section{NotAS DE AUTOR}

[1] Doctora en psicología. Profesora del Departamento de Psicología Básica, Evolutiva y de la Educación de la Facultad de Psicología (UAB). Ha sido jefa de área, y coordinadora de la Unidad de Atención Psicopedagógica. Su trayectoria científica y profesional ha girado en torno al ámbito de la psicología de la educación, centrada concretamente en: disciplina escolar, dificultades de aprendizaje y altas capacidades. Ha formado parte de diferentes proyectos de investigación nacional e internacional y realizado estancias en el extranjero, concretamente en Oxford University, Glasgow and Aberdeen University, Universidad de Oporto, compaginado su actividad laboral con conferencias. Entre sus principales publicaciones se incluyen: Gotzens, C., Cladellas, R., Clariana, M., Badia, M. (2015). Indisciplina Instruccional y convencional: Su predicción en el rendimiento académico. Revista Colombiana de Psicología, 24, 2, pp. 317-330. y Badia, M., Clariana,M.; Gotzens, M., Cladellas, R., Dezcallar, T. (2015). Videojuegos, televisión y rendimiento académico en alumnos de primaria. Pixel-Bit: Revista de medios y educación, 46. pp. 25-38.

[2] Profesora de Secundaria y Bachillerato de E.V.P. Tarragona, Cataluña. Máster en dificultades en el aprendizaje y trastornos del lenguaje (2016). UOC. Ha sido tutora y profesora de diversos grupos de educación secundaria obligatoria, desempeñando tareas propias de la materia y llevando a cabo proyectos dentro del centro educativo con estudiantes de la "aula abierta". Sus intereses versan sobre temas de disciplina escolar y dificultades de aprendizaje. 
evaluate the agents involved in the classroom, at a regular school, where disruptive students are present. From the results obtained, several proposals and methodological strategies were made for teachers allowing them to understand and be sensitive to the behavioral problems of some of their students, thus generating appropriate responses to their needs. From the observation and analysis of a 1st course of compulsory secondary education, 26 students were identified and considered disruptive due to their characteristics. Based on this, the consequences that this condition causes in routine operation and possible causes were addressed, and the perceptions students had about themselves in relation to disruptive situations were analyzed as well. The school staff in volved in the study (tutors, subject teachers, head teachers, principals, counseling department members, mediators and janitors) helped with interviews and questionnaires to reach useful conclusions to achieve the proposed objectives. Disruptive students' family characteristics, involvement and participation throughout the educational process have been useful elements to know about students' school perception, the classroom, the students and all the teachers in order to establish a valid series of tools to improve student behavior. From the data obtained, similar results regarding the relational dimensions (conflict) and the development dimension (autonomy and morality-religiosity)were observed. In regards to the stability dimension, both students and families attribute great importance to the organization and planning of the activities and family duties, and to a lesser extent the norms and procedures established within the family.

KEYWORDS: compulsory secondary school,, disruptive students, families, teachers, learning process.

\section{INTRODUCCIÓN}

La disciplina escolar es, en la actualidad, una de las principales preocupaciones a las que se enfrenta el profesorado tanto de enseñanza primaria como de secundaria. Pese a ello, la preparación que recibe durante el período de formación docente es casi inexistente (Melnick y Meister, 2008), ya que son escasos los centros que introducen dicha temática en su currículum oficial (Gotzens, Badia y Genovard, 2010). Por este motivo, el conocimiento disponible para afrontarla procede básicamente de sus creencias y sus experiencias y, en consecuencia, es de carácter vivencial y está falta de rigor (Gotzens, Castelló, Genovard y Badia, 2003).

La comunidad educativa reflexiona sobre los efectos y consecuencias de uno de los problemas en el ámbito educativo más relevantes, la disrupción escolar y los cambios sociales que se producen (Funes, 1998; Gimeno y Pérez, 1992; González, 2016). Tanto en escuelas como en institutos se resaltan las conductas disruptivas de estudiantes (Hardman y Smith, 2003; Ishee y James, 2004; Rodríguez y Petreñas, 2016), que afectan, sobre todo, su proceso de enseñanza-aprendizaje, pero también representan un grave problema por el trabajo que ha de realizar el personal docente.

Desde algunas posiciones, la responsabilidad de todo el problema recae en la función educadora de las familias y otros agentes educativos, y, desde el otro lado, las instituciones educativas son las responsables. La familia es el primer sistema social que conoce el niño y la niña, un espacio de seguridad, donde se desarrolla una organización concreta, y se marcan unas directrices determinadas, poco a poco van relacionándose con una red social que se amplía al sistema educativo, amistades, padres y madres, profesorado, medios de comunicación, y todo lo que les rodea, aproximándoles a la sociedad. Todos estos contextos son determinantes, ya que pueden favorecer o no su desarrollo.

En la niñez, la mayoría tiene control de sus palabras, impulsos, y expresiones, para resolver cualquier conflicto de una manera positiva, con una actitud constructiva; expresa sus emociones y es capaz de comunicarse con las otras personas sin provocar ningún tipo de conflicto, pues piensa, planifica, anticipa y organiza su acción; por otro lado, hay otra parte que resuelve muchas de las situaciones de manera agresiva, violenta y de poco autocontrol, dificultando el aprendizaje de un modelo adaptativo que le permita verbalizar los sentimientos, resolver los problemas de manera adecuada, tener conciencia ética, habilidades sociales y ser tolerante a la frustración. También actúa de forma intimidatoria con sus compañeros (Casas, Del Rey y Ortega-Ruiz, 2013; Tijmes, 2012). Por lo tanto, cualquier intervención en edad precoz puede ayudar a resolver los conflictos conductuales y que estos, a lo largo del tiempo, no queden atrapados en ciertos esquemas de comportamiento, y se convierta esto en un círculo inacabable de conflictos (Turecky y Tonner, 2003). 
En las escuelas e institutos, las conductas disruptivas a menudo son las que rompen el funcionamiento habitual del aula.

Peiró y Carpintero (1978, citados por Vallés, 1990) comentan que las conductas disruptivas pueden ser debidas a hábitos no aceptados socialmente, a dificultades personales de integración social y relación con los otros seres, a un nivel alto de agresividad, a enfrentamientos con el maestro o maestra, y a alteración de las normas de funcionamiento de la clase.

Fernández (2001) hace una clasificación más generalizada en cuatro categorías:

- No respetar las normas establecidas en el aula.

- Alterar el desarrollo de las tareas.

- Desafiar la autoridad.

- Agresión física o verbal.

Cualquier clasificación pone en evidencia que estas conductas problemáticas van en contra de los derechos personales tanto de estudiantes como de docentes. Estos comportamientos básicamente son de carácter motor, sin dejar de lado la estrecha relación que tienen con la dimensión cognitiva y afectiva (tanto de quien la provoca como de quien la recibe).

Las conductas problemáticas pueden acabar transformándose en trastornos de conducta como un grupo de problemas conductuales y emocionales que se suelen caracterizar de manera persistente y repetida durante un largo periodo de tiempo. Los encontramos tipificados en el Manual diagnóstico y estadístico de los trastornos mentales (DSM-5) (Asociación Americana de Psiquiatría, 2013) o en la clasificación internacional de enfermedades, décima versión (CIE-10):

El trastorno disocial (TD) es un conjunto persistente de comportamientos que evolucionan con el tiempo, se caracteriza por comportamientos en contra de la sociedad (antisociales) que violan los derechos de otras personas, las normas y reglas adecuadas para la edad (Vásquez, Feria, Palacios y de la Peña, 2010).

\section{LA ADOLESCENCIA Y SUS DIFICULTADES}

La adolescencia es una etapa exclusiva de los seres humanos, por lo tanto, hay una estrecha relación con las capacidades mentales superiores. Así pues, si bien es cierto que la acumulación de cambios, tanto fisiológicos como cerebrales y físicos, que se dan en la adolescencia puede generar cierta inestabilidad interna y conflictos internos y externos, también se produce un proceso, en parte invisible, de mayor reestructuración psicológica, en el ámbito relacional, en el ámbito cognitivo y en el ámbito de la identidad, que son claves para la conquista de la identidad personal.

La persona adolescente está vinculada a su historia personal, dentro de un contexto familiar, social y cultural concreto, en busca de una identidad propia. Poco a poco se va enfrentando al mundo desde una actitud activa y autónoma, donde consigue construir sus propios criterios, abandonando el estado de dependencia en relación con sus progenitores, donde tanto las amistades como otras personas adultas de referencia representan un papel clave en la construcción de esta identidad.

En constante evolución, los cambios que sufren pueden favorecer, minimizar o agravar la alteración de la conducta. Los posibles motivos de los problemas de conductas en adolescentes los podemos encontrar en el origen diverso que tienen, en las condiciones personales y contextuales que los mantienen. Su comportamiento, a menudo, es el reflejo de todas estas vivencias que han tenido; además, la carencia de confianza en el apoyo adulto y el miedo a cualquier participación pueden acentuar todavía más las relaciones y la dinámica en el aula.

Hay que recordar que en todo desarrollo hay una conjunto de factores de carácter tanto biológico, psicológico y social que generan una serie de elementos (internos y externos) que ayudan a modelar el 
desarrollo hacia un modelo adaptativo o bien de alteración de la conducta y de resiliencia. Estos factores generan influencias positivas que pueden llegar a anular el efecto de factores de riesgo.

Factores de protección:

- Habilidad elevada de crianza y educación.

- Personas de referencia estables.

- Estabilidad económica y social en el ámbito familiar.

- Ambiente social y escolar seguro y fiable.

- Expectativas positivas y atribuciones ajustadas.

- Éxito escolar.

- Presencia de conductas prosociales.

- A nivel escolar:

- Apoyo del entorno: amistades y docentes.

- Implicación del profesorado en la comprensión de su situación.

- Colaboración de la familia con el centro y con otros servicios.

- Confortar físicamente en los momentos de ansiedad.

- Conocer los recursos sanitarios y sociales del entorno.

- Método de enseñanza: adaptaciones curriculares funcionales y motivadoras cercanas a su realidad, actividades manipulativas, planificar el horario y agrupamientos.

- Pactos o compromisos pedagógicos (contratos) referentes al trabajo diario, actividades, deberes, responsabilidades, disciplina razonada.

- Reglas y normas de funcionamiento claras.

- Seguimiento individualizado (acompañamiento, conversación) (Jadue, Galindo y Navarro, 2005).

Hay una serie de factores de riesgo o vulnerabilidad que pueden contribuir a potenciar los comportamientos disruptivos; toda conducta tiene un trasfondo que, frecuentemente, responde a algo que es difícil de averiguar (Samuell, Alsina, Arroyo, 2011) y, a veces, pueden desarrollarse en alguno de los momentos de la vida adolescente:

- Ambientes de privación económica, emocional o social (estas situaciones son más graves en las áreas urbanas que en las rurales).

- Familias con normas educativas caóticas o negligentes.

- Padres y madres divorciados que mantienen una mala relación.

- Padres o madres con trastorno de personalidad antisocial, dependencia alcohólica u otros tóxicos.

- Situaciones de abuso o maltrato.

- Exposición a la violencia (hogar, calle, cine, televisión, videojuegos).

- Convicciones hacia el fracaso del alumnado.

- Sentimientos y actitudes de rechazo, negligencia o no estimación.

- Comorbilidad.

- Temperamento irascible.

- Síntomas de oposición y de desafío.

- Alta frecuencia y gravedad de conductas inadaptadas.

- A nivel escolar:

- Métodos de enseñanza: autoridad, indisciplinados y con niveles de exigencia desajustados (alto o bajo).

- Expulsiones reiteradas o exceso de permisividad. 
- Aislamiento social.

- Dinámica de la relación familia-centro.

- Mantener una relación positiva con la familia.

- Hechos traumáticos o desprecio de compañeros o compañeras, padres o madres, familia, entre otros.

- Retraso escolar.

\section{El profesorado como agente clave}

El profesorado es el encargado de gestionar el clima del aula, su gran responsabilidad es enseñar, ayudar, educar, sin dejar de lado la realidad y las necesidades de cada estudiante; debe entenderle como una persona en etapa de formación que necesita ayuda (ocultan una realidad, unos sentimientos, unos pensamientos) y ser sensible ante el sufrimiento que provoca este tipo de comportamiento, para lo cual no debe verle como un enemigo o enemiga, sino promover un entorno educativo favorable que ayude a la realización de una intervención educativa de regulación del comportamiento desde una perspectiva preventiva y proactiva.

Su función estará estrechamente ligada con el contexto de intervención, el sociocultural (estimulación del alumnado de tal manera que este sea el propio constructor de cultura), el institucional (donde tiene cabida el proyecto educativo de centro) y el instructivo (responsable de un clima social, quien organiza, planifica).

Las diferencias personales de cada docente le traen a aproximarse a su alumnado y al aula de varias maneras, así pues, cada uno interpreta según su percepción, su tolerancia, su experiencia personal, estrategias y control del aula. Esta diversidad ayudará a abordar el problema desde diferentes enfoques y servirá como aprendizaje profesional.

El personal docente está inmerso en un proceso educativo indeterminado, tanto la educación como el currículo están abiertos y han de ser flexibles ante posibles cambios en el aula, sin dejar de lado plantear una serie de objetivos e hitos para lograr. La práctica docente se considera, según Gimeno y Pérez (1992), como una actividad predefinida, un proceso indeterminado, complejo y multidimensional, caracterizado por la simultaneidad y, en cierto sentido, impredecible.

\section{El contexto}

El ámbito donde se desarrolla el alumnado es la escuela, la escuela inclusiva. Esta es una escuela para aprender en conjunto, para vivir en unidad, donde todo el mundo tiene cabida (todos los individuos aprendemos de todos), para conseguir desarrollarse como personas más autónomas. El objetivo es integrar al alumnado en el sistema educativo, sean las que sean sus características, tanto aquellos grupos con necesidades educativas especiales (trastornos graves de personalidad y conducta, enfermedades degenerativas graves), como aquellos con necesidades educativas específicas (estudiantes de incorporación tardía, con situaciones socioeconómicas desfavorecidas). Si hiciera falta, se tendría que garantizar la elaboración de un plan personalizado, y también la acogida de estudiantes de incorporación tardía (Cataluña. Ley 12/2009, del 10 de julio/de educación[LEC]. Diario Oficial de la Generalitat de Cataluña [DOGC], 16 de julio de 2009, en núm. 5422, p. 56629)

Por tanto, hablamos de aprendizaje no solo de conocimientos sobre las diferentes materias, sino también de desarrollar una serie de competencias básicas, conseguir que el alumnado adquiera las herramientas necesarias para entender el mundo en que está creciendo y que le guíen en su actuar; poner las bases para que sean personas capaces de intervenir activamente y críticamente en la sociedad plural, diversa y en continuo cambio, donde les ha tocado vivir. Además de desarrollar los conocimientos, capacidades, habilidades y actitudes (el saber, saber hacer, saber ser y saber estar) necesarios, tienen que aprender a movilizar todos estos recursos personales (saber actuar) para lograr la realización personal y así conseguir ser personas responsables, 
autónomas e integradas socialmente. La idea es que puedan ejercer la ciudadanía activa, incorporarse en la vida adulta de manera satisfactoria, ser capaces de adaptarse a nuevas situaciones y de desarrollar un aprendizaje permanente a lo largo de la vida (Gómez, 2011).

Para el buen funcionamiento de la escuela, habrá que respetar la normativa interna de centro, las normas de convivencia, los derechos y deberes de estudiantes y docentes, y las normas marcadas por cada docente en sus respectivas aulas. La disrupción altera el desarrollo normal del aula, provocando un caos donde se ven afectado el desarrollo-aprendizaje. Las normas de organización y funcionamiento de cada centro tienen que recoger cuáles son las faltas leves o graves y determinar las medidas correctoras oportunas, que contribuyan al proceso educativo.

La disciplina en el aula es un problema colectivo, puesto que se entiende que el grupo clase es la suma del conjunto de personas que hay y que desarrollan una serie de actividades, relaciones personales e interacciones. Se habla del buen funcionamiento del aula de manera grupal. Este buen funcionamiento se crea a partir de una serie de factores de relaciones sociales (estudiante-estudiante, docente- estudiante), de características físicas y ambientales de la propia aula, del propio centro. Según Jackson (1991), "las escuelas son contextos de interacción interpersonales tanto entre profesores y alumnos cómo de alumnos entre sí” (p. 46). Por este motivo, es conveniente identificar tanto los factores de protección como de riesgo de estudiantes con conductas disruptivas, para conseguir un entorno favorable en el aula que permita generar conductas apropiadas, de confianza, de seguridad y de tranquilidad.

La comunicación y la implicación en todo proceso educativo del alumnado por parte de las familias es básico. Y hay que remarcar que las funciones educadoras de ambas partes son diferentes. Hace falta, pues, reforzar la familia como el primer referente educativo y responsable del crecimiento y educación de los hijos e hijas.

\section{OBJetivos}

El objetivo principal ha sido evaluar a los agentes implicados en el aula en el marco de una escuela ordinaria, donde se presenta estudiantado disruptivo.

Los objetivos específicos se han centrado en:

1. Definir las conductas que generan disrupción en el aula y desfavorecen la enseñanza-aprendizaje.

2. Comprender los factores que influencian su surgimiento.

3. Analizar la percepción tanto del profesorado como del alumnado y familia, respecto al tema tratado.

4. Conocer las posibles relaciones entre alumnado disruptivo y familia

5. Ser capaz de identificar las conductas disruptivas, para poder hacer un plan de intervención coherente.

6. Elaborar una serie de propuestas, orientaciones que puedan favorecer su desaparición. Propuestas de actuación, tanto para el alumnado (a nivel individual y a nivel grupal), como para el profesorado o personas implicadas en el proceso de aprendizaje y para la familia.

7. Abrir la puerta a posibles nuevas investigaciones sobre el tema tratado.

Estos objetivos y expectativas implican las siguientes hipótesis de trabajo, a las cuales se pretende dar respuesta:

Hipótesis 1: El foco principal de la disciplina en las clases se centra básicamente en comportamientos propios del alumnado. Hipótesis 2: Los grupos adolescentes implicados en la disrupción en el aula tienen menor comunicación con la familia.

Hipótesis 3: La actitud del profesorado ante la disrupción es de castigo

Hipótesis 4: El alumnado percibe estos comportamientos como disruptivos o solo cuando hay sanciones por parte de los profesores. 


\section{Procedimientos metodológicos}

\section{Método}

La metodología empleada se basa en el contraste de los datos obtenidos a través de cuestionarios administrados a docentes y estudiantes de ESO, así como de las observaciones realizadas. Esta investigación se enmarca en una perspectiva empírico-analítica de carácter cuantitativo. Se trata de un estudio descriptivo.

El interés surge a partir de los problemas detectados con estudiantes de primero de educación secundaria obligatoria (ESO) de un instituto de la provincia de Tarragona (Cataluña), que han realizado la transición de la educación primaria a la educación secundaria, con todo lo que esto implica: cambio de pares de grupos, profesorado, ubicación, horario, materias, organización. A la vez, coincide con el cambio que presentan hacia la adolescencia. Funes (1998) comenta que "con la nueva situación escolar, coinciden al mismo tiempo dos procesos de transición: empiezan la adolescencia y empiezan la ESO. Con lo cual se sumarán dos inestabilidades, dos fuentes de estímulo y de inestabilidad, dos panoramas atractivos y contradictorios, dos procesos de adaptación” (p. 49), y la escuela tiene que dar respuesta a este proceso personal y escolar.

\section{Participantes}

La muestra está compuesta por 26 alumnos y alumnas de $1^{\circ}$ de ESO, 16 profesores y profesoras y 26 familias de instituto, todas personas enmarcadas dentro del sistema educativo español. El estudiantado que conforma esta muestra, son aquellos grupos que no han superado todas o parte de las competencias básicas de educación primaria y que en principio no se consideran conductuales, a excepción de los de la USEE (Unidad de Apoyo de la Educación Especial). Los criterios de agrupamiento del alumnado se determinaron para poder dar todos los recursos disponibles que ofrecía el instituto, estos criterios no están explicitados en el Plan de Atención a la Diversidad del centro, sino que se deciden por el conjunto del profesorado al final de cada curso.

Los recursos que proporciona el centro al grupo son los siguientes:

- En la mayoría de las materias están desdoblados (castellano, ciencias naturales, matemáticas, inglés, tecnología, ciencias sociales, catalán).

- El apoyo del EEE (docente de educación especial) de la USEE en algunas de las materias (educación visual y plástica y música).

- Psicopedagogas de la USEE por los 4 estudiantes USEE según dictamen EAP (Equipo de Asesoramiento y Orientación Psicopedagógica).

- Seminario de Orientación para trabajar los conflictos y conjuntamente con el equipo de mediación cuando es necesario.

- El grupo clase tiene dos tutoras.

\section{Instrumentos}

Para obtener la información necesaria para realizar la investigación, se aplicaron unos cuestionarios tanto para docentes, familias y estudiantes (más detallados posteriormente). A la vez que se realizó durante varias semanas observación en el aula para determinar estudiantes que podían ser disruptivos.

Con la información que se extrajo, se identificaron estudiantes con conductas disruptivas o sin estas, y se procedió a su evaluación, como la de sus docentes y sus responsables.

A los alumnos y alumnas: con objeto de evaluar las relaciones interpersonales entre miembros de la familia se administró la adaptación española de Moos, Moos y Trickett (1974), del cuestionario de clima social 
familiar (FES) y un pequeño cuestionario, con preguntas básicas del entorno más cercano, para conocer su situación familiar. Por poner un ejemplo, en este último cuestionario las preguntas hacían referencia a quién conformaba el núcleo familiar, nivel de estudios de los padres y madres, entre otras. Los alumnos y alumnas completaron los cuestionarios en sus clases, con la supervisión de una de las investigadoras. El cuestionario de clima social familiar permite evaluar las siguientes dimensiones:

- Dimensión de relaciones: El grado de comunicación y expresión en la familia (cohesión, expresividad, conflicto)

- Dimensión de desarrollo: Procesos de desarrollo personal (autonomía, actuación, intelectual/ cultural, social/recreativo, moralidad/religiosidad)

- Dimensión de estabilidad: La estructura y organización de la familia (organización, control)

Mediante la muestra del cuestionario se obtuvo información sobre: situación económica de la familia, miembros que la componen, relación de pareja, hábitos familiares, nivel educativo, relación familiar (padre/ madre/ responsable familiar-adolescente).

A las familias: con objeto de evaluar las características familiares también se administró la adaptación española del cuestionario de clima social familiar (FES) y un pequeño cuestionario para evaluar su percepción ante el comportamiento de estudiantes en el instituto

Al profesorado: con el fin de evaluar su percepción e implicación, se pasó la adaptación de Moos, Moos y Trickett (1987), del cuestionario CES de clima social-escolar (clima social relativo al centro y clima social relativo al profesorado) y un cuestionario para determinar la percepción que tiene el profesorado de la disrupción. El personal docente lo respondió en privado y lo entregó a la persona investigadora.

El objetivo fundamental de la escala CES es evidenciar las relaciones docente-estudiante y estudianteestudiante, así como el tipo de estructura organizativa del aula. La escala (original y la versión adaptada) cuenta con 90 ítems que miden 9 subescalas diferentes, comprendidas en cuatro grandes dimensiones:

- Dimensión relacional o relaciones: evalúa el grado de implicación del alumnado en el aula (implicación, afiliación, ayuda).

- Dimensión de desarrollo personal o autorrealización: valora la importancia de la realización de las tareas a realizar (tarea, competitividad).

- Dimensión de estabilidad o del sistema de mantenimiento: evalúa las actividades referidas al cumplimiento de los objetivos marcados (organización, claridad, control).

- Dimensión del sistema de cambio: evalúa el grado de novedad, diversidad en las actividades de aula (innovación) (Moos, Moos y Tricket 1989).

La participación tanto de las familias como del profesorado fue totalmente voluntaria y anónima.

\section{Procedimiento}

Se evaluó al alumnado a partir de la observación real en las aulas donde impartían las diferentes materias. En la hora de tutoría se les pasó un cuestionario donde se identificaron estudiantes con conductas disruptivas o sin estas.

Como base para determinar si un alumno o alumna presentaba o no disrupción, se estableció el siguiente criterio:

- Si tenía en más de una materia, más de un comportamiento perturbador que rompiera el ritmo habitual del aula.

- Conductas motoras. 
- Ruidos con objetos.

- Molestar a los compañeros o compañeras.

- Verbalizaciones disruptivas.

- Molestar físicamente a las otras personas.

- Pelearse.

Con el objetivo de poder diseñar un plan de intervención para el ámbito familiar / ámbito educativo/ ámbito personal, a las familias de estudiantes con conductas disruptivas o sin estas se les pasó un cuestionario para obtener información sobre las características familiares.

Otras consideraciones previas para la realización del estudio:

- El grupo de estudiantes no siempre recibe clase en la misma aula, utiliza las aulas de tecnología, de informática, aula ordinaria, aula consecutiva a su aula y aula de música. Hay que destacar que en el aula de música las sillas son de brazo y la distribución del espacio no permite el movimiento del profesor o profesora mientras imparte la materia y el alumnado dispone de muy poco espacio. En el resto de aulas, cada docente distribuye como cree conveniente para el trabajo diario de clase.

- La persona observadora no intervino para nada en las tareas habituales del aula, el estudiantado se comportó como si esta no estuviera presente.

\section{ANÁLISIS Y DISCUSIÓN DE LOS RESULTADOS}

En el siguiente apartado se describe el análisis de datos, necesario para dar respuesta a las hipótesis antes planteadas.

En un primer momento se revisaron las conductas disruptivas observadas en el aula en casi todas las materias del grupo. Se agruparon los resultados de las materias que desdoblaban, puesto que no se observaron resultados significativos entre un desdoblamiento y el otro.

Los resultados que se obtuvieron quedan reflejados en la Figura 1, donde se nos muestran la relación en cada una de las materias la cantidad de veces que el alumnado ha causado alguna de las disrupciones.

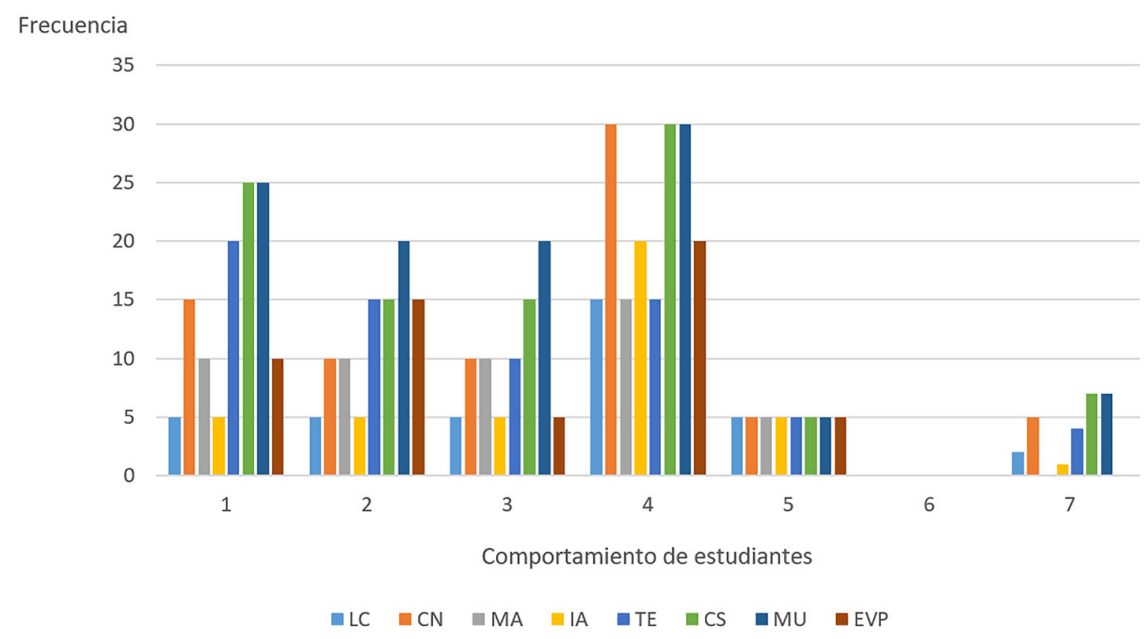

FIGURA 1

Observación del comportamiento de estudiantes en el aula.

Correlación de siglas: LC: Lengua catalana; CN: Ciencias naturales; MA: Matemáticas; IA:

Inglés; TÉ: Tecnología; CS: Ciencias sociales; MU: Música; EVP: Educación visual y plástica.

Los ítems analizados son los siguientes: 1. Motor, 2. ruidos con objetos, 3. molestar compañeros, 4. verbalizaciones, 5. molestar físicamente, 6. Pelearse, 7. Interrumpir en el aula. 
Observaciones realizadas en el aula que deben ser comentadas.

- El alumnado acostumbra permanecer en el pasillo mientras esperan al profesor o profesora, en general tiene una actitud de juego y se percibe una entrada en el aula caótica.

- El personal docente siempre pasa lista y espera a dar la consigna cuando el alumnado está callado y con orden. A menudo pasa un buen rato, pues antes no se pueda empezar.

- Antes de que el profesor o profesora dé la consigna de haber acabado la clase, la mayoría del alumnado ya tiene el material recogido.

- Se detecta un bajo grado de concentración una vez pasada la media hora.

- El alumnado no tiene ningún problema al preguntar a su docente si hay cualquier duda.

- El profesor o profesora a menudo se dirige a sus estudiantes por disciplina, explicación y consulta de dudas.

En segundo lugar, se evaluaron el clima familiar y el clima escolar percibidos por el alumnado. Se examinó la relación directa a partir del cuestionario FES.

En la Tabla 1 podemos apreciar las diferencias entre las diversas dimensiones obtenidas entre los 22 alumnos y alumnas.

TABLA 1

Resultados obtenidos del análisis de 22 estudiantes

\begin{tabular}{|c|c|c|c|}
\hline \multicolumn{4}{|l|}{ Clima familiar: estudiantes } \\
\hline \multirow{3}{*}{ Dimensión relacional } & Cohesión & CO: & 164 \\
\hline & Expresividad & EX: & 120 \\
\hline & Conflicto & CT: & 82 \\
\hline \multirow{5}{*}{ Dimensión de desarrollo } & Autonomía & AVE: & 104 \\
\hline & Actuación & AC: & 120 \\
\hline & Intelec-cultural & IC: & 124 \\
\hline & Social-recreativo & SR: & 112 \\
\hline & Moralidad-religiosidad & MR: & 106 \\
\hline \multirow{2}{*}{ Dimensión de estabilidad } & Organización & ORO: & 148 \\
\hline & Control & $\mathrm{CN}:$ & 112 \\
\hline
\end{tabular}

En tercer lugar, se hizo una evaluación del clima familiar percibido por familiares o personas responsables de estudiantes, examinando la relación directa, del cuestionario FEZ.

En la Tabla 2 se observan los resultados obtenidos por las familias. 
TABLA 2

Resultados obtenidos del análisis

\begin{tabular}{llll}
\hline Clima familiar: familias & & & \\
\hline \multirow{3}{*}{ Dimensión relacional } & Cohesión & CO: & 72 \\
\cline { 2 - 4 } & Expresividad & EX: & 63 \\
\cline { 2 - 4 } & Conflicto & CT: & 22 \\
\hline \multirow{4}{*}{ Dimensión de desarrollo } & Autonomía & AVE: & 43 \\
\cline { 2 - 4 } & Actuación & AC: & 58 \\
\cline { 2 - 4 } & Intelec-cultural & IC: & 50 \\
\cline { 2 - 4 } & Social-recreativo & SR: & 49 \\
\cline { 2 - 4 } & Moralidad-Religiosidad & MR: & 48 \\
\hline \multirow{2}{*}{ Dimensión de estabilidad } & Organización & ORO: & 79 \\
\cline { 2 - 4 } & Control & CN: & 51 \\
\hline
\end{tabular}

Del cuestionario sobre su percepción respecto al comportamiento del alumnado se derivan los siguientes resultados:

En la Figura 2 se observa el porcentaje de las familias que contestan afirmativamente las siguientes preguntas:

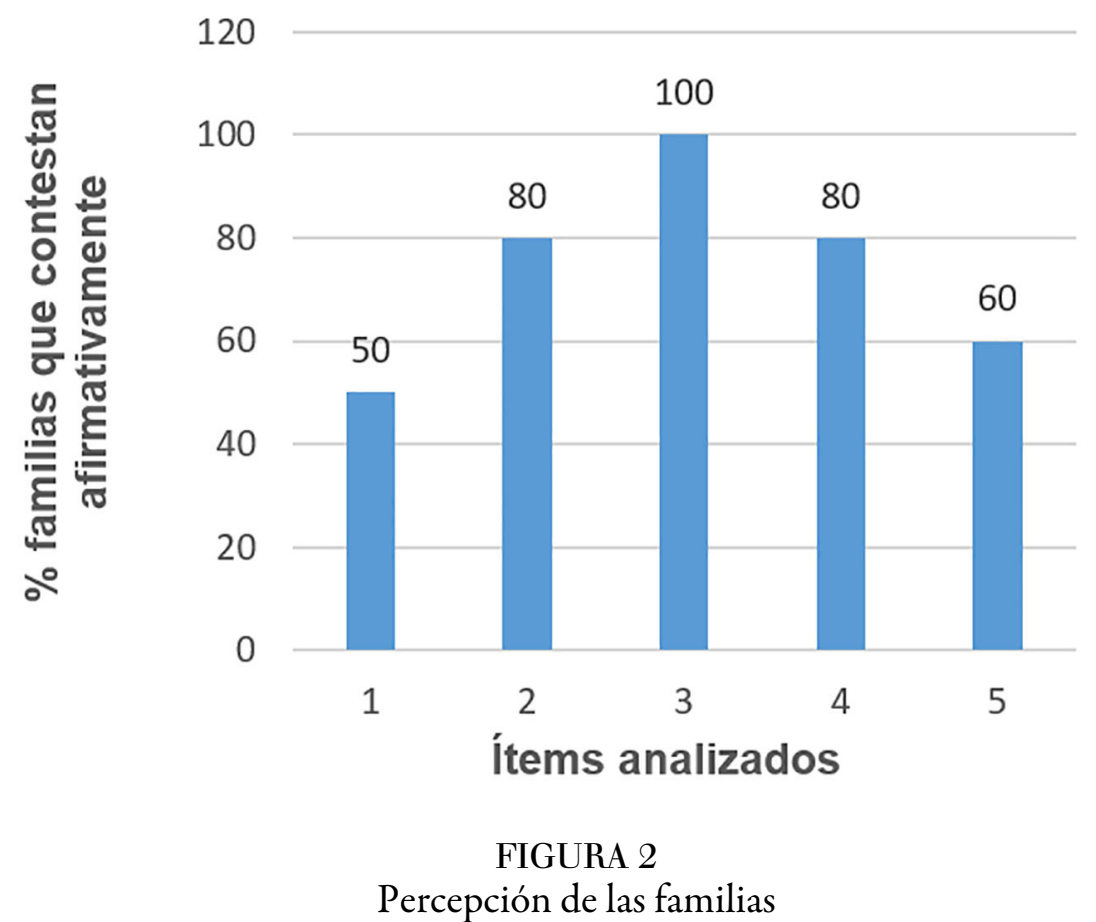

Ítems analizados: 1 . Se ha notado cambio entre primaria y secundaria; 2 . Hay causas de este posible cambio, 3. Hay bastante disciplina en el instituto, 4. Se puede mejorar el comportamiento del alumnado, 5. El comportamiento del alumnado disruptivo puede perjudicar la enseñanza-aprendizaje.

En la Figura 3 se muestra la percepción de las familias. 


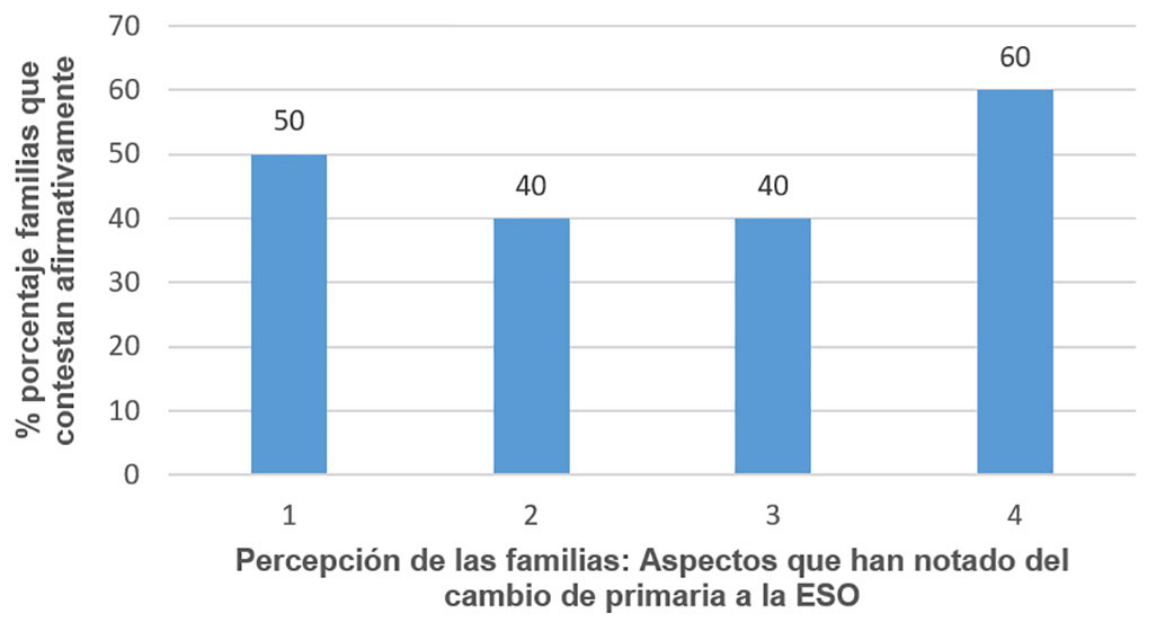

FIGURA 3

Percepción de las familias. Aspectos que han notado del cambio de primaria a la ESO.

Ítems analizados: 1. Debido a los cambios que se producen en la propia adolescencia, 2. Cambio de pasar de un círculo pequeño (escuela) a un círculo grande (instituto), 3. Los cambios de horario respecto a primaria, 4. Pensar que son autosuficientes y con más "poder" para hacer lo que quieran.

Ante la pregunta referida al comportamiento del alumnado tanto en casa como en la escuela, en cuanto a de qué manera mejorarían este comportamiento disruptivo, las respuestas de las familias quedan reflejadas en la Tabla 3.

TABLA 3

Percepción de las familias

\begin{tabular}{ll}
\hline Percepción de las familias \\
\hline $\begin{array}{l}\text { Como mejorar el } \\
\text { comportamiento } \\
\text { del alumnado }\end{array}$ & Menos móviles y ordenadores en los institutos. \\
& No tener siempre acceso a internet. \\
& Grupos heterogéneos para tener referentes positivos, remarcan la posibilidad de imitar \\
& actitudes negativas y acabar dejándose arrastrar por estas. \\
& Más vigilancia y control en las aulas, horas del patio. \\
& Que el profesorado sea más exigente. \\
& Utilización del castigo como medida correctora, tanto en casa como en la escuela. \\
& Enseñar los principios básicos y éticos que se tienen que cumplir y no discutirlos. \\
\hline
\end{tabular}

En cuarto lugar se evaluó la percepción e implicación de docentes con el alumnado, a partir de clima socialescolar (CES) y un cuestionario para determinar la percepción respecto al alumnado disruptivo.

Ante las preguntas realizadas del comportamiento del alumnado, se obtuvieron los siguientes resultados que se muestran en la Tabla 4. 
TABLA 4

Resultados obtenidos del análisis

\begin{tabular}{llll}
\hline Clima social en la escuela (CES) & & & \\
\hline \multirow{2}{*}{ Dimensión relacional } & Implicación & IM & 58 \\
\cline { 2 - 4 } & Afiliación & AF & 51 \\
\cline { 2 - 4 } Dimensión del desarrollo personal & Ayuda & AY & 74 \\
\cline { 2 - 4 } & Tarea & TA & 50 \\
\hline \multirow{2}{*}{ Dimensión de estabilidad } & Organización & ORO & 50 \\
\cline { 2 - 4 } & Claridad & CL & 86 \\
\cline { 2 - 4 } & Control & CN & 64 \\
\hline Dimensión del sistema de cambio & Innovación & IN & 52 \\
\hline
\end{tabular}

Ante el comportamiento del alumnado en el aula, en la siguiente tabla se especifican los resultados más significativos y con mayor puntuación (con valoraciones de mucho y bastante/normal) según percepción de más de la mitad del profesorado entrevistado.

En la Figura 5 encontramos los resultados en cuanto a la confirmación de normas.

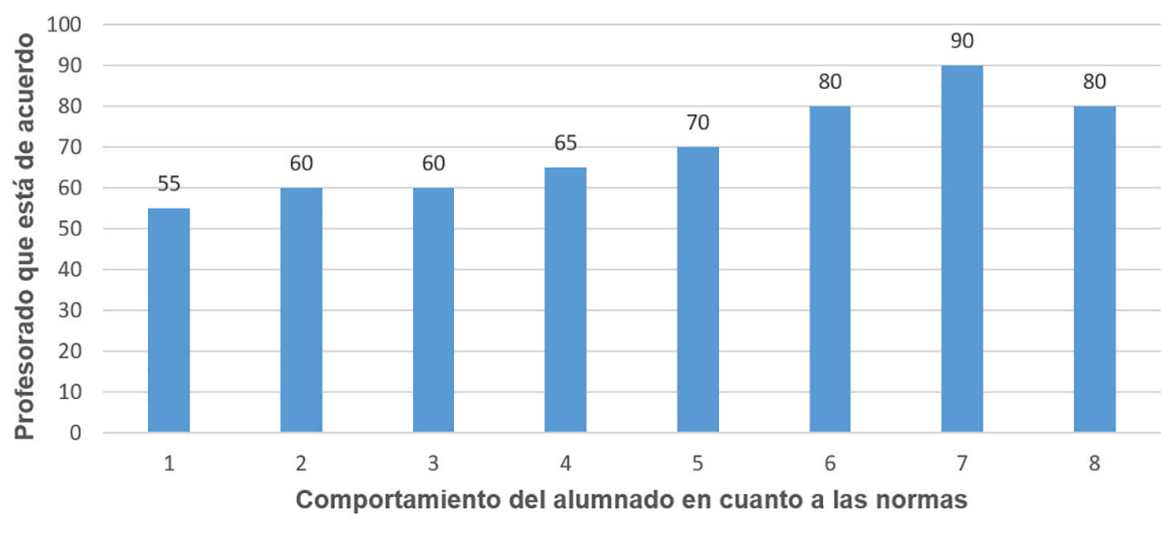

FIGURA 5

Comportamiento del alumnado en cuanto a las normas.

Ítems analizados: 1. Rallar mesas o paredes, 2. Echar cosas por la clase, 3. Pintar el libro o material proporcionado, 4. Escuchar música en Mp3 o móvil, 5. Jugar (hacer el “payaso”), 6. Hacer ruidos, 7. Chillar en clase, 8. Falta de orden de salida o entrada en la clase.

En la Figura 6 se muestra el comportamiento del alumnado referido al trabajo. 


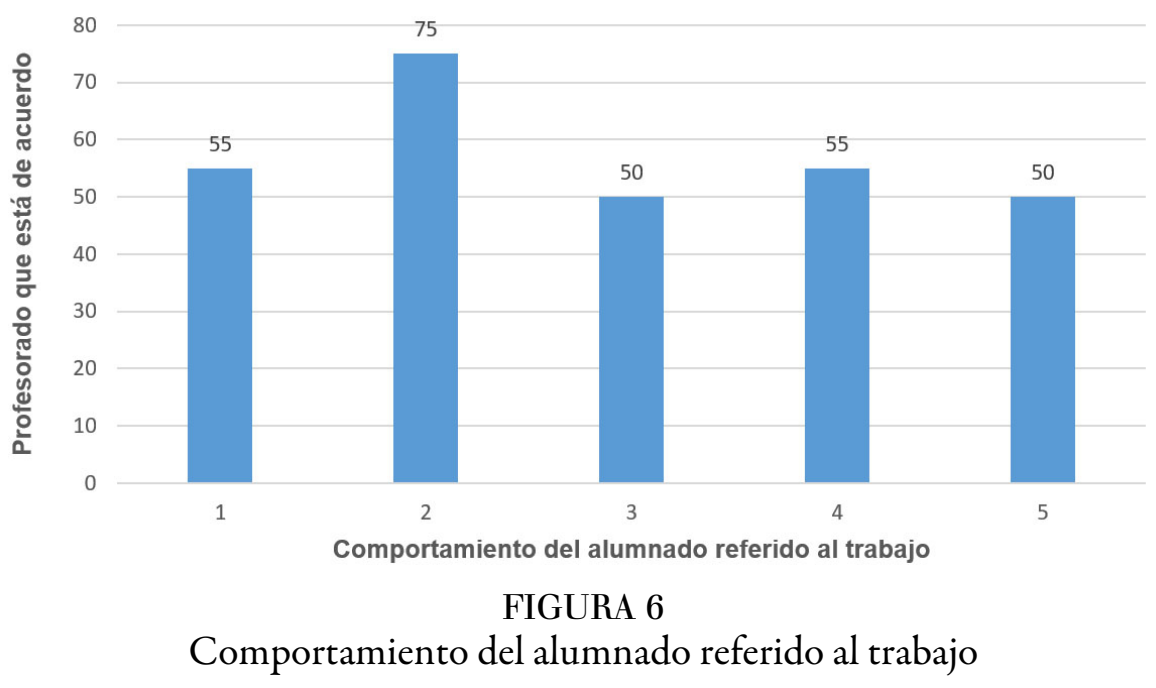

Ítems analizados: 1. No llevar los deberes, 2. Trabajo descuidado, 3. No traer el material, 4. Falta de interés, pasividad e inactividad, 5. Interrumpir con intención.

En la Figura 7 se refleja el comportamiento del alumnado en referencia al respeto al profesor.

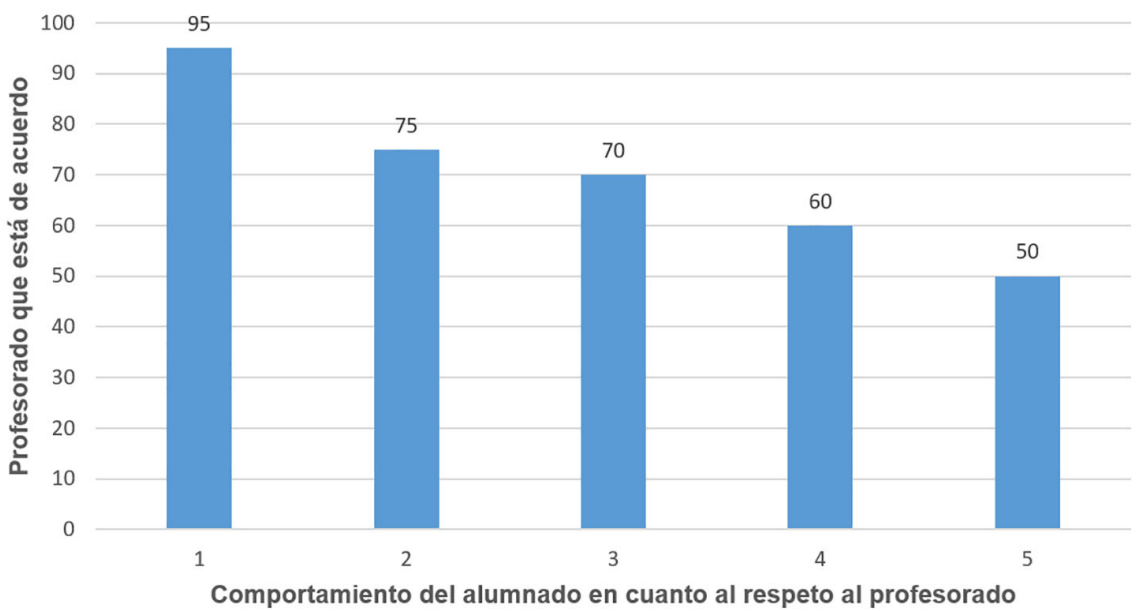

FIGURA 7.

Comportamiento del alumnado en cuanto al respeto al profesorado.

Ítems analizados: 1. Hablar cuando no toca, 2. No cumplir las órdenes, 3. Levantarse del lugar sin permiso 4. Guardar las cosas antes de tiempo, 5. Mentir.

En la Figura 8 se muestra el comportamiento del alumnado respecto a la relación con sus compañeros o compañeras. 


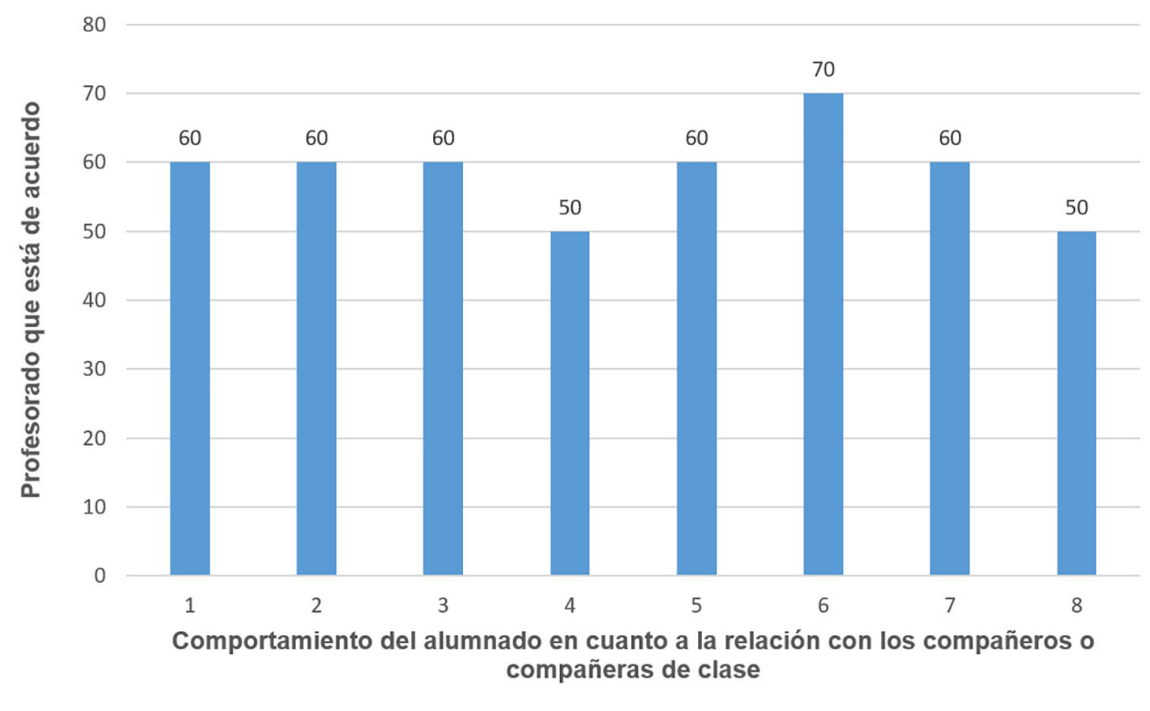

FIGURA 8.

Comportamiento del alumnado en cuanto a la relación con los compañeros o compañeras de clase.

Ítems analizados: 1. Pelearse, 2. Culpar a las otras personas, 3. Risas, 4. Destrozar las cosas de las demás personas, 5. Coger cosas sin permiso, 6. Insultar, 7. Pegar, 8. Hacer gestos o burlas.

Respecto a las cuestiones referidas al alumnado disruptivo se recogieron los siguientes resultados a destacar:

En la Figura 9 se reflejan los resultados sobre los componentes que perjudican dar clase en óptimas condiciones.

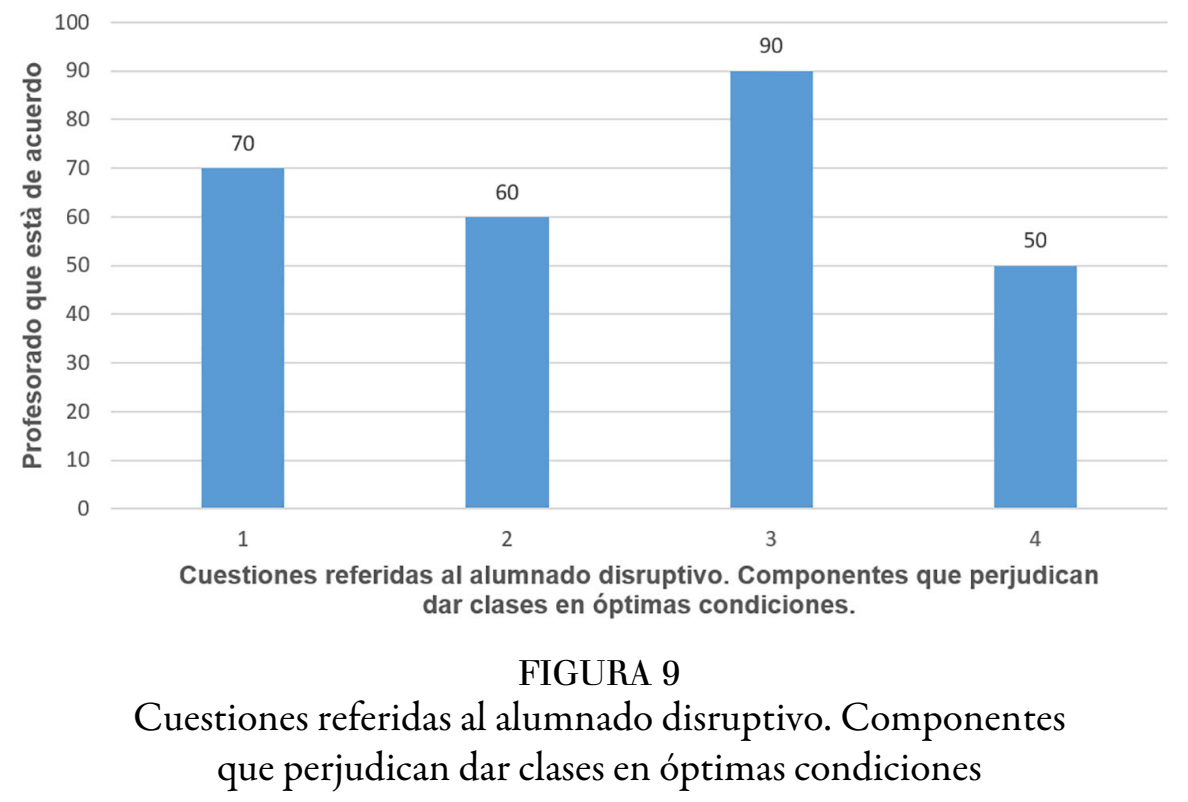

Ítems analizados: 1. Distracción, 2. Dispersión, 3. Número elevado de estudiantes en las aulas, 4. Ruidos fuera del aula (calle, otras aulas...).

En la Figura 10 se muestran cuestiones referidas al alumnado disruptivo. 


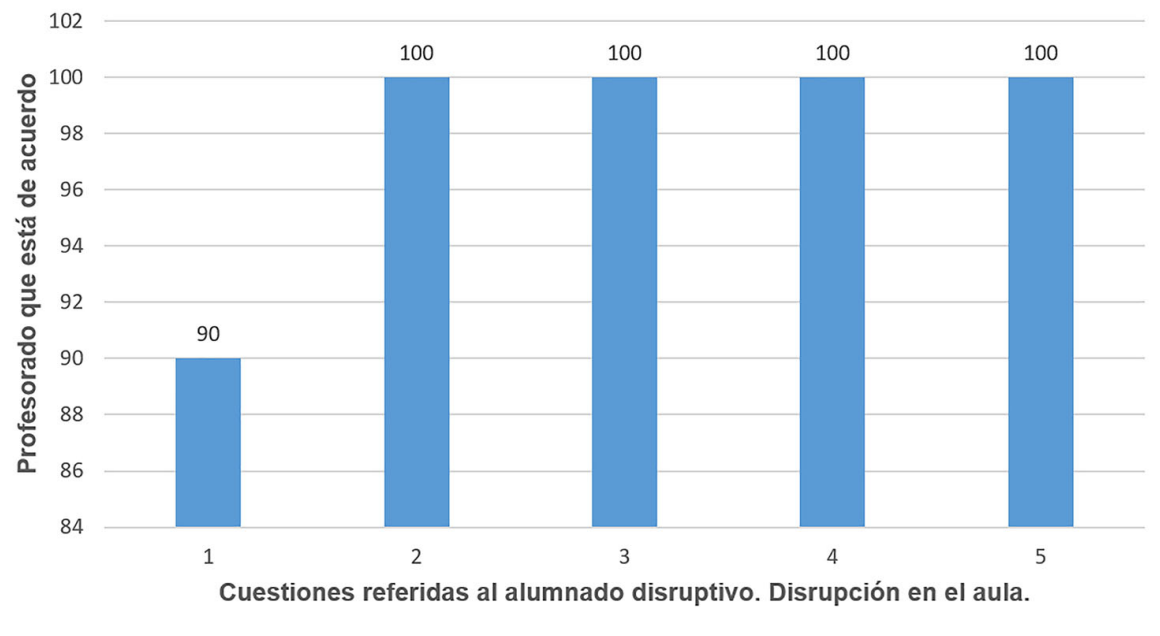

FIGURA 10

Cuestiones referidas al alumnado disruptivo. Disrupción en el aula.

Ítems analizados: 1. Hay disrupción en el aula, 2. La provocan siempre o casi siempre el mismo alumnado, 3. La sufren más docentes, 4. Es positivo tener el grupo partido o dos docentes en el aula, 5. Se dispone de herramientas para afrontar la disrupción.

En la Figura 11 se muestran las herramientas y recursos con las que se cuenta.

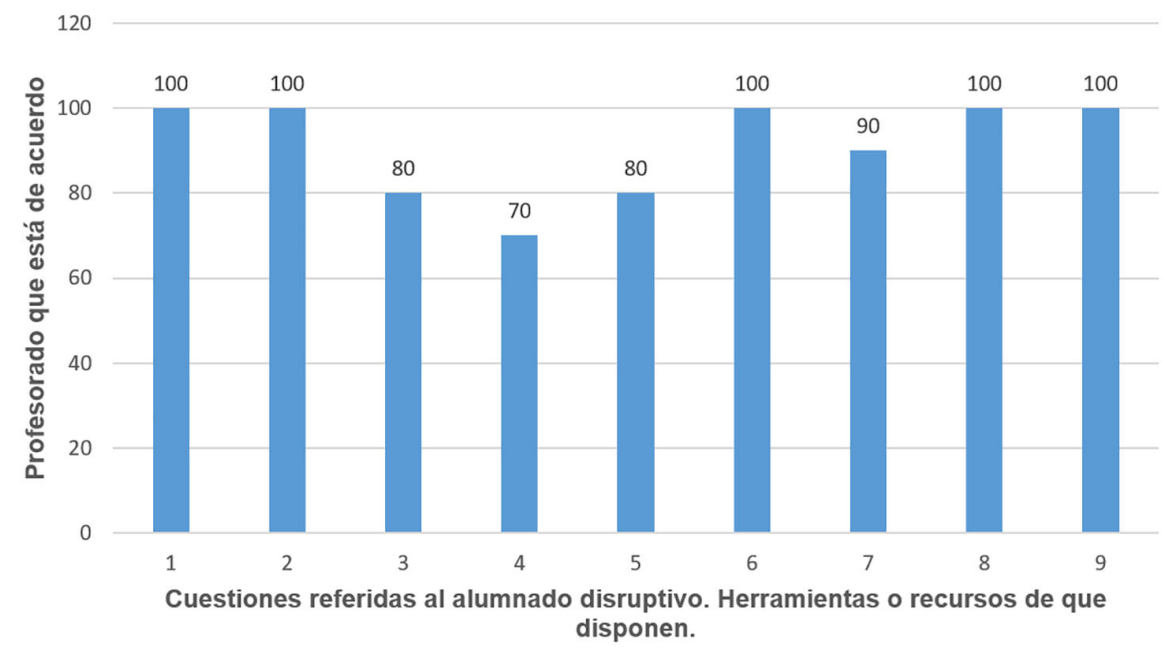

FIGURA 11

Cuestiones referidas al alumnado disruptivo. Herramientas o recursos de que disponen.

Ítems analizados: 1. Apoyo del centro, 2. Protocolo de convivencia del centro, 3. Recursos personales, 4. Reforzamiento positivo al alumnado de los pequeños éxitos conseguidos, 5 . Reconocer las buenas conductas en el alumnado, 6. Otro profesor o profesora en el aula, 7. Castigo como medida correctora, 8. Conversación con el alumno o alumna, 9. Contacto con la familia.

Ante las preguntas referidas a la disrupción se realizaron varias cuestiones que quedan reflejadas en la Tabla 5. 
TABLA 5

Cuestiones referidas al alumnado disruptivo

\begin{tabular}{|c|c|}
\hline \multicolumn{2}{|c|}{ Cuestiones referidas al alumnado disruptivo } \\
\hline $\begin{array}{l}\text { ¿Por qué hay } \\
\text { disrupción? }\end{array}$ & $\begin{array}{l}\text { Motivos sociales y familiares } \\
\text { Estudiantes no tienen claro los límites. } \\
\text { Poca motivación. } \\
\text { Falta de hábitos. }\end{array}$ \\
\hline $\begin{array}{l}\text { Como } \\
\text { solucionar el } \\
\text { problema de } \\
\text { la disrupción }\end{array}$ & $\begin{array}{l}\text { Que todo el equipo docente trabaje en la misma dirección. } \\
\text { Menos alumnado en las aulas puesto que permite focalizar mejor la atención, atender } \\
\text { cada una de las individualidades. } \\
\text { Mejorar el funcionamiento de las clases. } \\
\text { Adquirir una actitud más positiva y abierta. } \\
\text { Trabajar por proyectos, trabajo corporativo, trabajo individual. }\end{array}$ \\
\hline
\end{tabular}

\section{DiSCUSIÓN Y CONCLUSIONES}

Llegados a este punto y a partir de los resultados que se obtuvieron en la administración de las pruebas y el análisis respecto a la observación directa del aula se puede concluir que el alumnado:

- Interrumpe el funcionamiento habitual del aula con verbalizaciones en una elevada frecuencia; destaca, básicamente, hablar cuando no corresponde, sin respetar el turno de palabra y hablar con sus pares.

- Con bastante frecuencia tiende a tener comportamientos de carácter motor, como levantarse sin permiso, cosa que desfavorece la actividad diaria en el aula.

- Con menos frecuencia hace ruidos con objetos.

- Acostumbra a molestar a los compañeros y compañeras tirando papeles, dando golpecitos con las piernas y cogiéndoles material.

- Interrumpe, una vez empezada la clase, a sus pares en busca de materiales tales como: el estuche, el ordenador, la libreta o la bolsa con el material, e incluso al mismo profesorado por motivos diversos.

Respecto al análisis de respuesta a partir del cuestionario Escalera de clima social familiar (Family Envoironment Scale FEZ), tanto del alumnado como de las familias se pueden observar unos resultados muy parecidos respecto a la dimensión relacional (conflicto) y a la dimensión de desarrollo (autonomía y moralidad-religiosidad).

- Sobre la dimensión relacional que evalúa el grado de comunicación y libre expresión dentro de la familia cabe remarcar la baja puntuación directa en la subescala de conflicto donde el alumnado y las familias perciben poco grado de expresión de manera libre y abiertamente a la ira, a la agresividad y al conflicto entre integrantes de la familia. Por otro lado, se destaca la importancia que se le da al grado de compenetración y de ayuda entre sí, el grado en que se permite y se anima a miembros de la familia a actuar de manera libre y a expresar de manera directa sus sentimientos.

- En cuanto a la dimensión del desarrollo que evalúa el grado de importancia de ciertos procesos de desarrollos personales, se observa que tanto el alumnado como las familias no sienten seguridad en sí, les cuesta tomar sus propias decisiones y no son bastante autosuficientes, donde destacan la poca importancia que se le da a los valores tanto éticos como morales. Por otro lado, hay un cierto interés por las actividades y participación en las actividades políticas, intelectuales y culturales.

- En relación con la dimensión de estabilidad, esta nos proporciona información sobre la estructura y organización de la familia y sobre el grado de control que normalmente ejercen unos miembros sobre otros. Tanto el alumnado como las familias dan mucha importancia a la organización y planificación 
de las actividades y responsabilidades de la familia, y con menos grado al que hace referencia a las normas y procedimientos establecidos en la misma familia.

El análisis del clima social de la escuela (CES) implica la percepción del ambiente en el aula: "una de las motivaciones más fuertes de la investigación del clima escolar, es la de poner de relieve, las percepciones de los/las alumnos/as en determinados aspectos del ambiente donde reciben la educación y variables tales como el rendimiento académico, la satisfacción, la cohesión grupal, la organización de la clase, etc." (Cassuolo, Álvarez y Pasman, 1998, p. 187).

El profesorado, ante la dimensión relacional, que evalúa el grado de implicación, libertad de expresión y apoyo entre estudiantes, que muestra cuán integrados o no están los grupos, destaca, con la máxima puntuación obtenida, la subescala de ayuda, donde el profesorado presenta una fuerte preocupación por sus estudiantes. Por otro lado, se refleja un menor grado de afiliación, pues se percibe un nivel de amistad y apoyo entre estudiantes muy ajustado.

En la segunda dimensión, donde se valora la importancia de las tareas y los temas en el aula, destaca la baja puntuación de la importancia que se le da al conseguir una buena calificación y aprecio, como también en la dificultad para obtenerlas (subescala competitividad). A su vez, y no demasiado valorada, el énfasis que el mismo profesorado pone en el temario de las materias (subescala tarea).

Respecto a la dimensión de estabilidad, que evalúa las actividades relativas al cumplimiento de los objetivos, funcionamiento adecuado de la clase, organización claridad y coherencia, se sitúa por encima de la media en las subescalas de claridad (importancia que se le da al seguimiento de las normas y a sus consecuencias), y control (grado en que el profesorado hace cumplir las normas), exceptuando la subescala de organización (importancia que se le da al orden, organización y buenas maneras en la realización de las tareas de la escuela) que se sitúa justo en la media.

Ante la dimensión del sistema de cambio, se observa una puntuación ajustada respecto a la contribución estudiantil a plantear actividades escolares y la variedad y cambios que introduce el mismo profesorado con nuevas técnicas y estímulos para la creatividad (subescala innovación). Como señala De la Torre (1993), el aprendizaje creativo hace referencia al conocimiento construido con la implicación activa del sujeto, desde su planificación a su interiorización, caracterizado por la motivación intrínseca, el estar centrado del sujeto discente, el carácter abierto del proceso y la autoevaluación.

De los cuestionarios antes mencionados se puede concluir que el profesorado muestra una cierta preocupación por todas las conductas disruptivas, sobre todo en lo referente a las normas en cuando a jugar, hacer ruidos, llamar, falta de orden en la salida y entrada del aula.

Así pues, según la primera hipótesis planteada en que el foco principal de la disciplina se centra básicamente en el comportamiento estudiantil, se puede concluir que intervienen varios factores tanto de carácter social, familiar, del ambiente que les rodea, y que todos ellos van estrictamente relacionados con el comportamiento propio del alumnado.

Según la segunda hipótesis sobre la relación entre estudiantado disruptivo y la falta de comunicación con la familia, se observa que existe una relación directa entre la percepción de estudiantes y las familias de lo que sucede en casa, aunque no podemos determinar si esta relación de clima social familiar influencia de manera directa en el comportamiento del alumnado en el aula.

Respecto a la tercera hipótesis planteada sobre la actitud del profesorado en cuanto al castigo, se concluye que la mayoría utiliza otros recursos para afrontar la disrupción en el aula, aunque el castigo forma parte de él. También hay que destacar que las familias ven bien y apoyan el castigo como medida correctora.

Según la cuarta hipótesis sobre la percepción que tiene el alumnado como comportamientos disruptivos, se refleja que la mayoría de estudiantes no llega a ser consciente de la cantidad de disrupciones que realiza en el aula, y no percibe su comportamiento negativo (disrupción) cuando el profesorado les hace reflexionar o emite una sanción. 
A partir de los resultados obtenidos se elaboraron una serie de propuestas y estrategias metodológicas para docentes, con el propósito de que les permitiera entender y sensibilizarse de la problemática conductual de algunos grupos de sus estudiantes, y generara respuestas adecuadas a sus necesidades. Estas se basaron en la creación de materiales, asesoramiento metodológico-temporal, y en breves cursos de formación para los maestros y maestras que deseaban mejorar.

\section{CONSIDERACIONES FINALES}

En referencia a los problemas y limitaciones que se han encontrado en el presente trabajo, cabe destacar la falta de implicación a la hora de responder a las preguntas por parte de docentes y familia, hecho bastante significativo.

Dado el periodo en que se desarrolló la investigación, quedan aspectos interesantes para evaluar en posteriores estudios. Sería necesario disponer de más tiempo para poder observar no solo un grupo concreto, sino realizar una observación de todo el instituto, para así determinar las posibles causas de la disrupción en todo el centro educativo, donde sería necesaria la implicación de todo el profesorado, estudiantes y familias. Al mismo tiempo, sería necesario disponer de un plan de intervención que afecte a todo el centro, de manera que forme parte del currículo, donde la participación del profesorado y la coordinación con las familias permitiera desarrollar un proyecto futuro.

En conclusión, conviene seguir investigando sobre las causas de la disrupción, de la manera cómo afrontarla y solucionar los problemas, dando herramientas reales y, de ser posible, poderlas aplicar y ver si los resultados mejoran el comportamiento y, por lo tanto, el proceso de enseñanza- aprendizaje. Según Gotzens et al. (2010, pp. 41), es conveniente que los programas de formación integren elementos válidos para trabajar y modificar creencias y valores, además de información conceptual y procedimental que expanda el conocimiento de los sujetos sobre las disciplinas.

\section{ReFERENCIAS}

Asociación Americana de Psiquiatría. (2013). Manual diagnóstico y estadístico de los trastornos mentales (5a ed.). Arlington: Editorial Médica Panamericana. doi: https://doi.org/10.1176/appi.books.9780890425596.807874

Casas, J. A., Del Rey, R., y Ortega-Ruiz, R. (2013). Bullying and cyberbullying: Convergent and divergent predictor variables. Computers in Human Behavior, 29(3), 580-587. doi: https://doi.org/10.1016/j.chb.2012.11.015

Cassullo, G. L., Alvarez, L. V. y Pasman, P. (1998). Adaptación de las escalas de clima social escolar y familiar. VI Anuario de Investigaciones, 186-198.

De la Torre, S. (1993). La creatividad en la aplicación del método didáctico. En M. L. Sevillano y Martín, F. (Coords.), Estrategias metodológicas en la formación del profesorado (pp. 287-309). Madrid: UNED.

Fernández, I. (2001). Guía para la convivencia en el aula. Barcelona: Ciss-Praxis.

Funes, J. (1998). Escolarización obligatoria i adolescencia. Educar, 22-23, 99-118. doi: https://doi.org/10.5565/rev/ educar.350

Gimeno, J. y Pérez, A. (1992). Comprender y transformar la enseñanza. Madrid: Morata.

Gómez, M. R. (2011). El modelo educativo basado en competencias en el bachillerato mexicano y el desarrollo de habilidades de información. Revista Chilena Infoconexión. 2, 1-28. Recuperado de http:// eprints.rclis.org/15777/1/Infoconexion N² Gomez Sustaita María.pdf

González, F. J. (2016). Educación y cambio social: Aportes desde la pedagogía crítica. Revista Electrónica Diálogos Educativos, 16(31), 137-150. Recuperado de http://revistas.umce.cl/index.php/dialogoseducativos/article/ view/1008 
Gotzens, C., Castelló, A., Genovard, C. y Badia,M. (2003). Percepciones de profesores y alumnos de E.S.O. sobre la disciplina en el aula. Psicothema, 15(3), 362-368. Recuperado de http://www.deciencias.net/ convivir/1.documentacion/D.disrup.normas/Percepciones_disciplina_aula(2003)7p.pdf

Gotzens, C., Badia, M., Genovard, C. (2010). Conocimiento de los profesores sobre disciplina escolar. Boletín de Psicología, 99, 33-44. Recuperado de https://www.uv.es/seoane/boletin/previos/N99-2.pdf

Hardman, E. L. y Smith, S. (2003). Analysis of Classroom Discipline-Related Content in Elementary Education Journals. Behavioural Disorders, 28(2), 173-186.

Ishee, J. H. y James, A. R. (2004), Perceptions of Misbehaviour in Middle School Physical Education. Journal of Physical Education, Recreation and Dance, 75(1), 9. doi: https://doi.org/10.1080/07303084.2004.10608530

Jackson, P. H. (1991). La vida en las aulas. Madrid: Morata.

Jadue, G.,Galindo, A. y Navarro, L. (2005). Factores protectores y factores de riesgo para el desarrollo de la resiliencia encontrados en una comunidad educativa en riesgo social. Estudios Pedagógicos, 31(2), 43-55. Recuperado de http://mingaonline.uach.cl/pdf/estped/v31n2/art03.pdf

Llei d'Educació de Catalunya (LEC). Decret 12/2009, de 16 de juliol. Núm 5422 pàg 56629. Diari Oficial de la Generalitat de Catalunya. Recuperado de http://portaldogc.gencat.cat/utilsEADOP/PDF/5422/950599.pdf

Melnick, S. A. y Meister, D. G. (2008). A Comparison of Beginning and Experienced Teachers' concerns. Educational Research Quarterly, 31 (3), 39-56. Recuperado de https://files.eric.ed.gov/fulltext/EJ788428.pdf

Moos, R. H., Moos, B. S. y Tricket, E. J. (1989). Escalas de clima social, familia (FES), trabajo (WES), instituciones penitenciarias (CIES), centro escolar (CES). Manual (3a ed.). Madrid: TEA.

Moos, R. H., Moos, B. S. y Tricket, E. J. (1974). The social climate Scales: Family Environment Scale (HAZ). Palo Alto: Consulting Psychologist Press.

Rodríguez, L. y Petreñas, C. (2016). Interacciones y apoyo educativo inclusivo en el desarrollo del yo del alumnado con problemas conductuales: un estudio de caso en un contexto inclusivo. Revista Electrónica Diálogos Educativos, 16(31), 49-71. Recuperado de http://www.dialogoseducativos.cl/revistas/n31/rodriguez.pdf

Samuell, C., Alasina, G. y Arroyo, A. (2011). Alumnado cono dificultadas de regulación del comportamiento (Vol.1): Infantil y primaria. Barcelona: Escalón. Recuperado de http://blocs.xtec.cat/diversitatconducta/2012/05/06/ bibliografia-alumnado-conodificultadas-de-regulación-del-comportamiento/

Tijmes, C. (2012). Violencia y clima escolar en establecimientos educacionales en contextos de alta vulnerabilidad social de Santiago de Chile. PSYKHE, 21(2), 105-117. doi: https://doi.org/10.7764/psykhe.21.2.548

Turecky, S. y Tonner, L. (2003). El niño difícil: Cómo comprender y tratar a los niños difíciles de educar. Barcelona: Medici.

Vallés, A. (1990) Modificación de la conducta problemática del alumnado. Técnicas y programas. Alcoi: Marfil.

Vásquez, J., Feria, M., Palacios, L. y de la Peña, F. (2010). Guía clínica para el trastorno disocial. México: Instituto Nacional de Psiquiatría Manuel de la Fuente.

\section{BY-NC-ND}

